\title{
Nódulos fibro-histiocíticos no baço de uma cadela: relato de caso
}

\author{
[Splenic fibroistiocytic nodules in a bitch: case report] \\ B.C. Garmatz ${ }^{1}$, A.M. Viott ${ }^{2}$, C.F. Silva ${ }^{2}$, A. Mazzanti ${ }^{2}$, I.M. Santarosa ${ }^{2}$, A.T. Ramos ${ }^{2}$ \\ P.C. Maiorka ${ }^{3}$, D.L. Graça ${ }^{2} *$ \\ ${ }^{1}$ Aluno de graduação - UFSM - RS \\ ${ }^{2}$ Universidade Federal de Santa Maria \\ Avenida Roraima, 1000 \\ 97105-900 - Santa Maria, RS \\ ${ }^{3}$ Faculdade de Medicina Veterinária e Zootecnia - USP - São Paulo, SP
}

\begin{abstract}
RESUMO
Descreve-se a ocorrência de múltiplos nódulos fibro-histiocíticos no baço de uma cadela Rottweiler, de sete anos. O diagnóstico foi feito por histopatologia e confirmado por imunoistoquímica positiva para ED1, CD18, vimentina e lisozima. O animal foi sacrificado três meses após o diagnóstico, por severo agravamento dos sinais clínicos.
\end{abstract}

Palavras-chave: cão, baço, neoplasia, nódulo fibro-histiocítico

\begin{abstract}
Multiple fibrohistiocytic nodules in the spleen of a 7-year-old female Rottweiler were reported. The diagnosis was made by histology and immunohistochemistry; cells were positive for ED1, CD18, vimentin and lysozyme. The dog was euthanatized three months after the tumor was diagnosed, due to severe clinical signs.
\end{abstract}

Keywords: dog, spleen, neoplasia, fibrohistiocytic nodule

\section{INTRODUÇÃO}

Os nódulos fibro-histiocíticos (NFH) e a histiocitose maligna compõem a grande maioria dos casos de neoplasias primárias do baço, que são constituidos principalmente por histiócitos neoplásicos. Apesar da origem controversa, os NFH são classificados como neoplasias pleocelulares, ou seja, são tumores formados a partir de duas origens celulares distintas, uma fibroblástica e a outra histiocitíca (Spangler e Kass, 1998). As raças mais suscetíveis são as de grande porte como Rottweilers, Boxer (Rogers et al., 1994), Montanhês de Berna (Ramsey et al., 1996), Pastor Alemão, Cocker Spaniel, Labrador Retriever e Golden Retriever (Vail, 2001). Poodles e raças mistas também podem ser acometidas (Spangler e Kass, 1998).
Os cães acometidos apresentam apatia, perda de peso acentuada, vômitos e por vezes diarréia. $\mathrm{Na}$ palpação abdominal pode-se perceber uma massa firme e irregular na porção media do abdômen. No exame radiográfico aparece como uma massa amorfa de formato irregular e densidade leve na área do baço (Rogers, et al., 1994). Esses nódulos são detectados por ultra-sonografia como nódulos hipoecóicos, que por vezes distorcem as bordas do órgão (Spangler e Kass, 1998).

As células tumorais da linhagem histiocítica são marcadas com anticorpos para lisozima, antitripsina alfa-1 humana, antiquimiotripsina alfa-1, mac387, catepsina B e CD18 (Vail, 2001). A origem mesenquimal do tumor é confirmada devida à forte marcação pela vimentina (Morris et al., 2002).

Recebido em 22 de agosto de 2005

Aceito em 5 de março de 2007

*Autor para correspondência (corresponding author)

E-mail: dlgraca@smail.ufsm.br 


\section{CASUÍSTICA}

Uma cadela Rottweiler, de sete anos de idade, foi apresentada com histórico de anorexia, polidipsia, poliúria, prostração e perda da consciência por vários minutos. $\mathrm{O}$ hemograma estava normal e o leucograma acusou leucocitose por neutrofilia. A bioquímica do sangue mostrou gamaGT 6,0, creatinina $1,1 \mathrm{mg} / \mathrm{dl}$ e FA de 1,16UL/1. Ao exame clínico, foi detectado baço aumentado, e a radiografia confirmou a esplenomegalia (Fig. 1), demonstrando contornos arredondados do órgão. $\mathrm{O}$ exame ecográfico demonstrou esplenomegalia moderada, órgão de contornos irregulares, parênquima hipoecogênico com áreas anecogênicas difusas. (Fig. 2). Foi sugerida a laparotomia exploratória e realizada a esplenectomia.

Macroscopicamente, o baço media $35 \times 6 \times 12 \mathrm{~cm}$ de largura, e a superfície natural era protruída por numerosos nódulos de 0,4 a $4,0 \mathrm{~cm}$ de diâmetro (Fig. 3A). Na superfície natural do baço e na superfície de corte, esses nódulos variavam de cor bronzeada a esbranquiçada, variegada de cor de vinho (Fig. 3B). Tinham consistência macia a friável. Fragmentos de vários nódulos foram clivados e incluídos em parafina, cortados com $5 \mu \mathrm{m}$ de espessura, e corados com hematoxilina-eosina (Culling et al., 1985).

O exame histológico revelou proliferação de células fusiformes em padrão de redemoinhos amplos (Fig. 4A). Por vezes as células apresentavam formas intermediárias entre fibroblastos e células epitelióides, com formação de células gigantes multinucleadas (Fig.4B). O índice mitótico era de três mitoses por campo de grande aumento e havia infiltrado linfóide linfoplasmocitário difuso discreto a moderado e eritrofagocitose (Fig. 4C). Na imunoistoquímica, a marcação foi intensamente positiva para vimentina (Fig. 5A), e positiva para lisozima (Fig. 5B), ED1 (Fig. 5C) e CD18 (Fig. 5D) demonstrando a origem mesenquimal e histiocítica da neoplasia.

Com prognóstico desfavorável o animal recebeu alta. Retornou três meses mais tarde com histórico de anorexia e andar cambaleante. As radiografias de tórax e abdome mostraram a presença de massas radiopacas circunscritas na região caudal do hilo pulmonar (Fig. 6A) e no abdômen, compatíveis com linfoadenomegalia (Fig. 6B), prováveis metástases do tumor diagnosticado anteriormente. Foi solicitada a eutanásia, porém o proprietário não permitiu a necropsia.

\section{DISCUSSÃO}

Os NFH esplênicos do cão são constituídos por população histiocítica e de células fusiformes numa proporção variável com plasmócitos e/ou linfócitos. Existem diferentes teorias para explicar a origem dos NFH, mas acreditava-se que essa neoplasia era derivada de macrófagos/monócitos ou de uma linhagem miofibroblástica primitiva. Mas, ao que tudo indica, os NFH parecem representar uma forma transicional e continua entre hiperplasia nodular e neoplasia dos componentes pleocelulares (linfócitos, plasmócitos e histiócitos) (Spangler e Kass, 1998).

Num estudo em 100 cães com tumores malignos primários do baço, os NFH responderam pela maioria dos casos de esplenomegalia nessa espécie. Os animais mais afetados eram fêmeas de raças de grande porte, tinham em média 10 anos e aproximadamente $21 \mathrm{~kg}$ de peso (Rogers et al.,1994). Embora, a ocorrência de NFH tenha sido relatada em cães de grande porte, da raça Poodle e de raças mistas, os cães raça Montanheses de Berna são os mais acometidos pelas lesões histiocíticas nodulares ou disseminadas (Moore, 1984; Moore e Rosin, 1986; Ramsey et al., 1996).

O prognóstico em todas as raças é desfavorável pela ocorrência de metástases disseminadas. O tempo médio de sobrevivência, após o diagnóstico, é de cinco meses (Vail, 2001), e as metástases são comuns no fígado, pulmões, linfonodos, rins e omento, embora também sejam vistas na medula óssea, no coração, no esôfago, na medula espinhal e na próstata (Waters et al., 1994; Spangler e Kass, 1999). Neste caso, a necropsia não foi autorizada pelo proprietário, mas a presença de linfonodos grandemente aumentados de volume em tórax e abdômen sugere disseminação sistêmica da tumoração. 


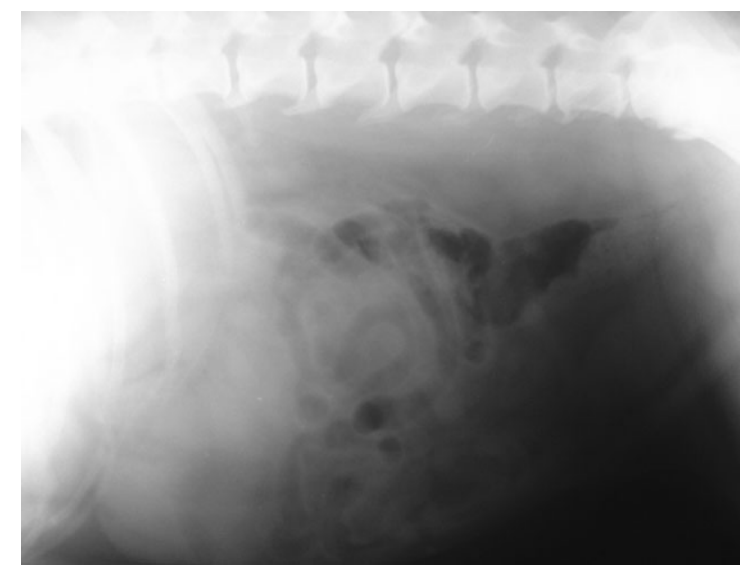

Figura 1. Radiografia em projeção lateral evidenciando esplenomegalia. As bordas do baço estão proeminentes e arredondadas (seta).

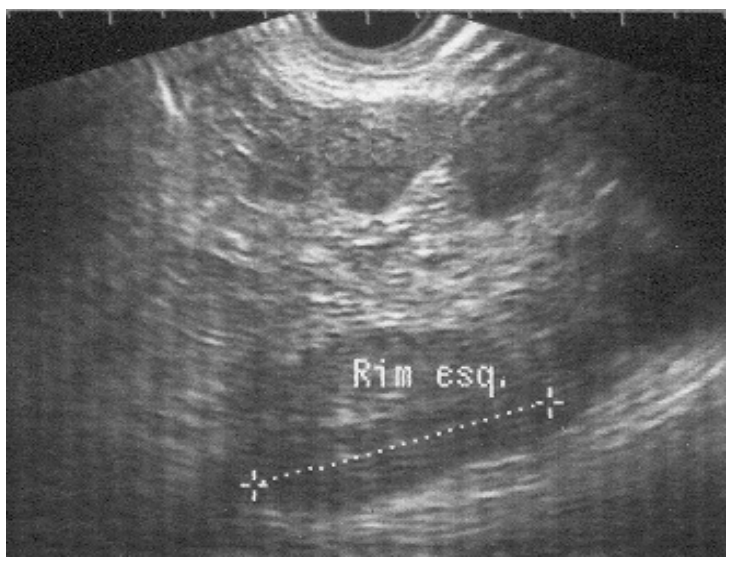

Figura 2. Baço com parênquima hipoecogênico. Áreas anecogênicas difusas sugerindo nódulos (seta).

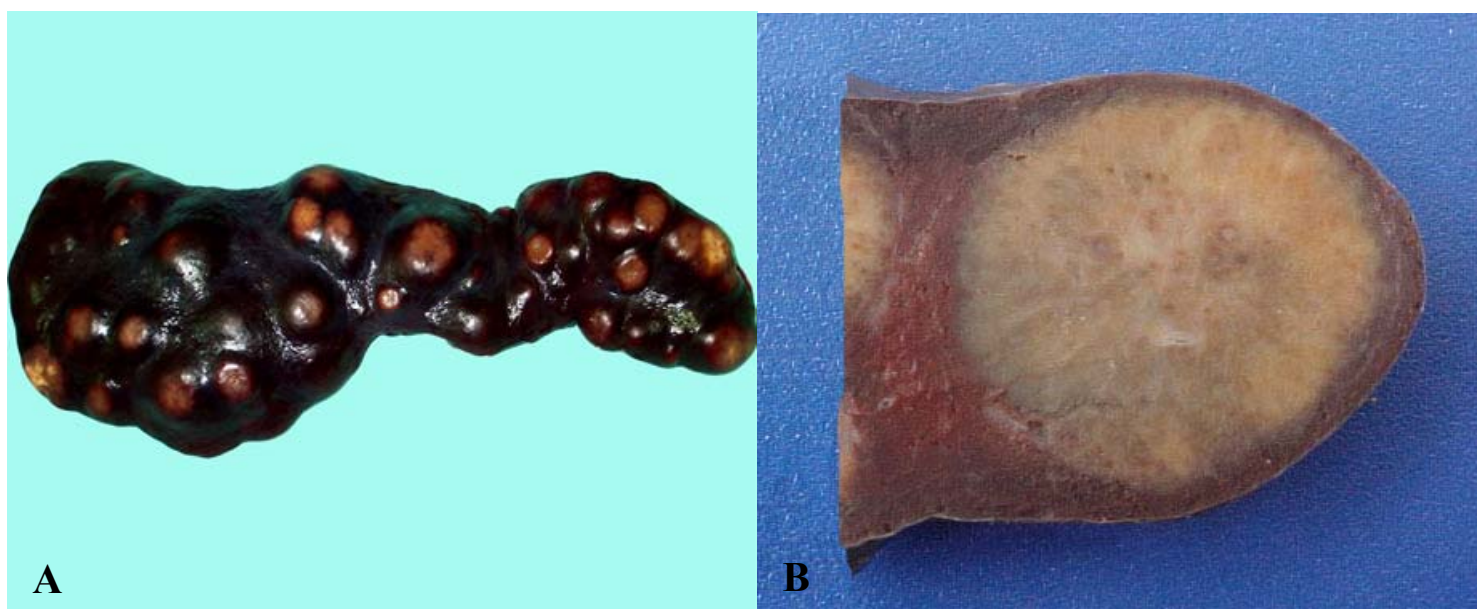

Figura 3. A) Baço com nódulos fibro-histiocíticos, 35×6×12 $\mathrm{cm}$ de largura, e superfície natural protruída por numerosos nódulos de 0,4 a 4,0 cm de diâmetro. B). Na superfície natural do baço e na superfície de corte, esses nódulos variavam de cor bronzeada a esbranquiçada, variegada de cor de vinho.

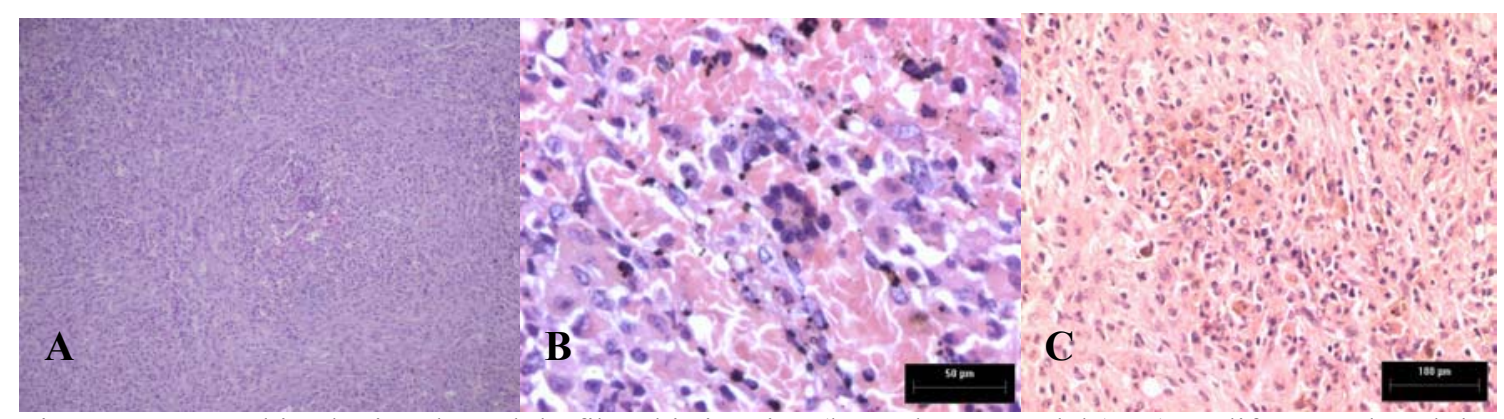

Figura 4. Exame histológico de nódulo fibro-histiocítico (baço de uma cadela): A) proliferação de células fusiformes em padrão de redemoinhos amplos (HE 10x). B) células com formas intermediárias entre fibroblastos e células epitelióides, formação de células gigantes multinucleadas (HE 40x). C) infiltrado linfóide linfoplasmocitário difuso discreto a moderado e eritrofagocitose. Indice mitótico=3 mitoses/campo (HE 40x). 

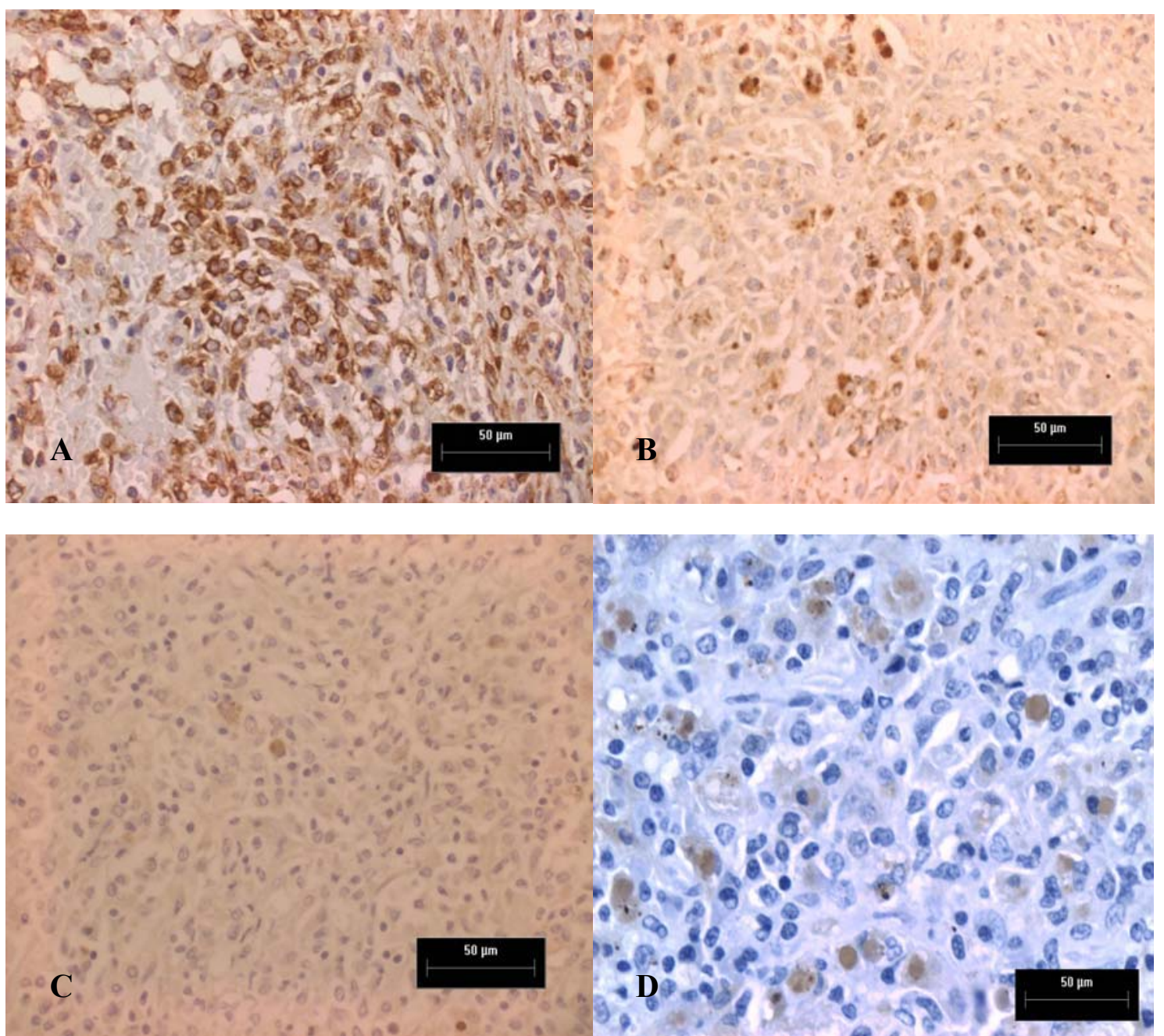

Figura 5. Imunoistoquímica (corte histológico de nódulo fibro-histiocítico - baço de uma cadela). Marcação intensamente positiva para vimentina (A) e lisozima (B) (IHQ 40x). C) ED1 (IHQ 20x) e D) CD18 (IHQ 40x) demonstrando a origem mesenquimal e histiocítica da neoplasia.

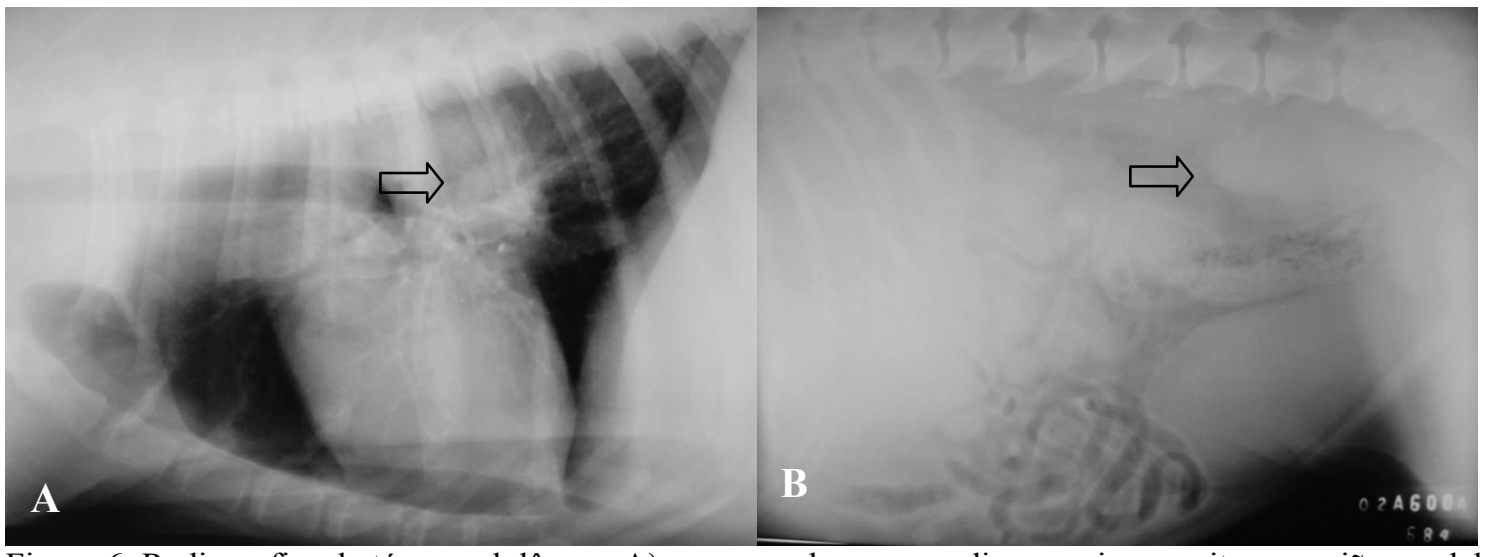

Figura 6. Radiografias de tórax e abdômen. A) presença de massa radiopaca circunscrita na região caudal do hilo pulmonar e no abdômen; B) linfonodos aumentados de volume (setas). Prováveis metástases de tumor (nódulo fibro-histiocítico no baço de cadela). 
O diagnóstico clínico de esplenomegalia e a suspeita de NFH são reforçados pelos exames radiográfico e ultra-sonográfico (Rogers et al., 1994). Tal como é citado na literatura (Spangler e Kass, 1999), os dados clínicos não foram de ajuda no diagnóstico neste caso. Após a macroscopia ter sugerido uma entidade diversa de simples nódulo linfóide hiperplásico, a microscopia mostrou a verdadeira origem da tumoração.

Histologicamente, os NFH consistem de células semelhantes a fibroblastos e a histiócitos, entremeadas, em varias porções, com quantidades variáveis de plasmócitos e linfócitos, por vezes formando um manto celular ou redemoinhos amplos. Há graus variados de atividade mitótica, eritrofagocitose, trombose e infartos (Vail, 2001). Em geral, o tamanho do nódulo é dado pelo incremento de células fibrohistiocíticas e linfóides que se unem uniformemente à proliferação tumoral. A análise microscópica dos NFH pode exibir cinco variações morfológicas diferentes: pleomórfica, mixóide, inflamatória, angiomatosa e de células gigantes (Thoolen et al, 1992). No presente caso, o aspecto pleomórfico predominou devido à presença de células gigantes, infiltrado linfoplasmocitário e grande quantidade de tecido conjuntivo.

Na microscopia eletrônica, as células neoplásicas são ovais ou poligonais e apresentam o retículo endoplasmático rugoso dilatado, e ocasionalmente, macrófagos com características fibroblásticas. Entretanto, algumas células demonstram um citoplasma proeminente com filamentos, que podem ser consideradas células com diferenciação miogênica ou miofibroblástica (Spangler e Kass, 1998).

O uso de técnicas imunoistoquímicas permite a diferenciação dos NFH de outros tumores de células fusiformes do cão (Pérez et al., 1996). No caso, foram realizadas marcações específicas para as células tumorais. A positividade concomitante da vimentina, ED1, CD18 e lisozima confirma a origem mesenquimal e histiocítica das células. A presença de linfócitos e plasmócitos completa o diagnóstico de NFH. Outros marcadores histiocíticos como a antitripisina $\quad \alpha-1$, antiquiniotripsina $\quad \alpha-1 \quad$ e catepsina $B$, podem também ser utilizados para determinar histiócitos (Ramsey et al., 1996).
No diagnóstico diferencial, os NFH devem ser considerados, pois aumentos focais de volume do baço de cães, na maioria das vezes, consistem de nódulos linfóides hiperplásicos (Spangler et al., 1992).

As doenças proliferativas de histiócitos no cão compreendem um largo espectro de doenças com comportamento biológico variado, sem etiologia e/ou patogenia elucidadas. Essas incluem o histiocitoma cutâneo, a histiocitose sistêmica e a histiocitose maligna (Affolter e Moore, 2002; Moore e Rosin, 1986).

O histiocitoma cutâneo é um tumor benigno, freqüentemente encontrado em cães jovens, que responde bem à excisão cirúrgica. Histopatologicamente, os histiocitomas caracterizam-se por folhas uniformes e cordões de células histiocíticas pleomórficas infiltrando a derme e a subcútis, deslocando as fibras colágenas anexas (Pires, 1997).

A histiocitose sistêmica é uma doença crônica debilitante comum em cães da raça Montanhês de Berna de meia idade, e é caracterizada pelo envolvimento da pele, linfonodos periféricos, olhos e outros tecidos. Os sinais clínicos incluem anorexia, perda de peso, estertor respiratório, e pápulas. $\mathrm{O}$ curso pode ser prolongado e flutuante com episódios de exacerbação e remissão. $\mathrm{Na}$ microscopia, podem-se observar infiltrações perivasculares superficiais e profundas de histiócitos citologicamente normais (Ramsey et al., 1996).

Em contraste com a histiocitose sistêmica, a histiocitose maligna freqüentemente atinge cães velhos, da raça Montanhês de Berna. Esses animais geralmente têm sinais clínicos sistêmicos não específicos, os olhos e a pele raramente estão envolvidos. A histiocitose maligna é caracterizada por múltiplos nódulos sólidos pálidos mais comumente encontrados no baço, fígado, linfonodos e pulmões (Ramsey et al., 1996). À semelhança do observado histiologicamente com os NFH, são observados histiócitos, células com morfologia de histiócitos ativados (epitelióides) e células gigantes num arranjo frouxo. Em distinção não há a presença de fibroblastos, linfócitos e plasmócitos entremeados com a proliferação descrita acima (Kerlin e Hendrick, 1996). 


\section{REFERÊNCIAS BIBLIOGRÁFICAS}

AFFOLTER, V.K.; MOORE, P.F. Localized and disseminated histiocytic sarcoma of dendritic cell origin in dogs. Vet. Pathol., v.39, p.74-83, 2002

CULLING, C.F.A.; ALLISON, R.T.; BARR, W.T. Cellular pathology technique. 4.ed. London: BUTTERWORTHS, 1985. p.111-152

KERLIN, R.L.; HENDRICK, M.J. Malignant fibrous histiocytoma and malignant histiocytosis in the dog: convergent or divergent phenotypic differentiation? Vet. Pathol., v.33, p.713-716, 1996.

MOORE, P.F. Systemic histiocytosis of Bernese Mountain dogs. Vet. Pathol., v.21, p.554-563, 1984.

MOORE, P.F.; ROSIN, A. Malignant histiocytosis of Bernese Mountain dogs. Vet. Pathol., v.23, p.1-10, 1986

MORRIS, J.S.; McINNES, E.F.; BOSTOCK, D.E. et al. Immunohistocheminal and histopathological features of 14 malignant fibrous histiocytomas from Flat-coated Retrievers. Vet. Pathol., v.39, p.74-83, 2002

PÉREZ, J.; BAUTISTA, M.J.; ROLLÓN, E. et al. Immunohistochemical characterization of hemagiopericytomas and other splindle cells tumors in the dog. Vet. Pathol., v.33, p.391-397, 1996

PIRES, M.A. Malignant fibrous histiocytoma in a puppy. Vet. Rec., v.140, p.234-235, 1997.

RAMSEY, I.K.; McKAY, J.S.; RUDORF, H. et al. Malignant histiocytosis in three Bernese mountain dogs. Vet. Rec., v.138, p.440-444, 1996
ROGERS, K.S.; HELMAN, R.G.; HURLEY, K.J. et al. Splenic malignant fibrous histiocytoma in two dogs. J. Am. Anim. Assoc., v.30, p.253256, 1994

SPANGLER, W.L.; CULBERTSON, M.R.; KASS, P.H. Primary mesenchymal (Nonangiomatous/Nonlymphomatous)

neoplasms occurring in the canine spleen: anatomic classification, immunohistochemistry, and mitotic activity correlated with patient survival. Vet. Pathol., v.31, p.37-47, 1992.

SPANGLER, W.L.; KASS, P.H. Pathologic and prognostic characteristics of splenomegaly in dogs due to fibrohistiocytic nodules: 98 cases. Vet. Pathol., v.35, p.488-498, 1998

SPANGLER, W.L.; KASS, P.H. Splenic myeloid metaplasia, histiocytosis, and hypersplenism in the $\operatorname{dog}(65$ cases $)$. Vet. Pathol., v.36, p.583-593, 1999.

THOOLEN, R.J.M.M.; VOS, J.H.; VAN DER LINDE-SIPMAN, J.S. et al. Malignant fibrous histiocytomas in dogs and cats: an immunohistochemical study. Res. Vet. Sci., v.53, p.198-204, 1992.

VAIL, D.M. Miscellaneous tumors. Histiocytic disorders. In: WITHROW, S.J.; MacEWEN, E.G. (Ed). Small animal clinical oncology. Philadelphia: Saunders, 2001. p.667-671

WATERS, C.B.; MORRISSON, W.B.; DENICOLA, D.B. et al. Giant cell variant of malignant fibrous histiocytoma in dogs: 10 cases (1986-1993). J. Am. Vet. Assoc., v.205, p.14201424, 1994. 